\title{
Complete right- and left-sided thoracic ducts associated with aberrant left vertebral artery: unreported case with surgical implications
}

\author{
N. Eid, Y. Ito, S. Futaki, Y. Kondo \\ Department of Anatomy and Cell Biology, Division of Life Sciences, Osaka Medical College, Osaka, Japan
}

[Received: 13 April 2017; Accepted: 21 May 2017]

\begin{abstract}
Anatomy is the keystone to an appropriate understanding of surgical and radiological sciences. Here the authors report on a rare case of complete right- and left-sided thoracic ducts (TDs) associated with aberrant left-vertebral artery (LVA) arising from the aortic arch. The TDs originated from right and left cisterna chyli and terminated separately close to the left venous angle. Superior to the aortic arch, the TDs showed different relationships to the LVA; the right TD was ventral, while the left was dorsal in position. This report is associated with other variations detailed below, and may have important implications in cervicothoracic surgery. (Folia Morphol 2018; 77, 1: 156-160)
\end{abstract}

Key words: thoracic duct, aberrant vertebral artery, chylothorax

\section{INTRODUCTION}

As thoracic ducts (TDs) have long been linked to essential normal or anomalous neurovascular structures, injuries to such ducts or related structures may cause complications in various surgeries and interventional procedures involving the duct and/or associated anomalous structures $[4,5]$. Variations of the arterial system are rare compared to venous system, and may complicate various surgeries [6, 7]. Accordingly, appropriate knowledge of vertebral artery variations may be indispensable in thoracic aortic surgery [10]. Based on anatomical and radiological research, various patterns (including TD duplication) have been highlighted in different studies $[1,8,11]$. However, studies showing the coexistence of complete TD duplication associated with aberrant leftvertebral artery (LVA) and other variations (such as accessory renal/mental vessels, accessory muscles and a unilateral absence of musculocutaneous nerves) have not yet been reported.

\section{CASE REPORT}

During the superior mediastinum dissection of an elderly Japanese man in the Anatomy Department (total number of dissected bodies: 27, including this case) of Osaka Medical College, the presence of aberrant LVA arising from the aortic arch between the left common carotid and subclavian arteries was noted. Interestingly, the LVA was crossed ventrally and dorsally by two TDs, terminating close to the left venous angle. The superficial (right) TD emerged from the deep surface of the oesophagus, passing between the LVA and left common carotid artery, while the deeper one (left) passed deep to the left subclavian artery close to its origin from the aortic arch (Fig. 1). Deeper dissection showed that the two

Address for correspondence: N. Eid, PhD, MD, Junior Associate Professor, Department of Anatomy and Cell Biology, Division of Life Sciences, Osaka Medical College, 2-7 Daigaku-machi, Takatsuki, Osaka 569-8686, Japan, tel: +81 726831221 ext. 2630 , fax: +81 726846511, e-mail: nabil@osaka-med.ac.jp; nabileidm@yahoo.com

Meeting presentation: This work was orally presented during the $122^{\text {nd }}$ annual meeting of the Japanese Association of Anatomists on March 28 , 2017, in Nagasaki, Japan. 


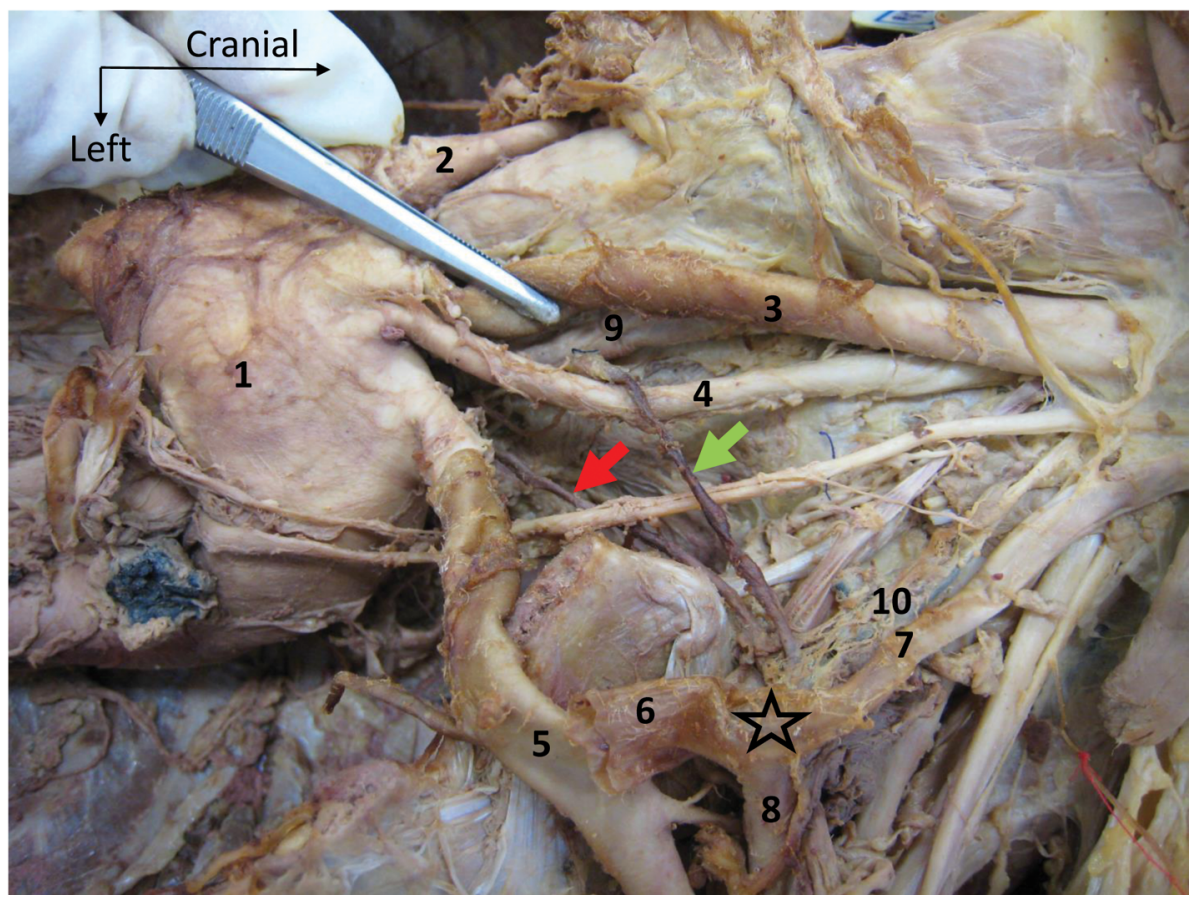

Figure 1. Dissection of the cervicothoracic region showing cervical parts of right and left thoracic ducts (green and red arrows, respectively). The black star indicates the left venous angle; 1 - aortic arch; 2 - innominate artery; 3 - left common carotid artery; 4 ; left-vertebral artery; 5 — left subclavian artery; 6 — left innominate vein; 7 — left internal jugular vein; 8 — left subclavian vein; 9 - oesophagus; 10 - Virchow lymph node.

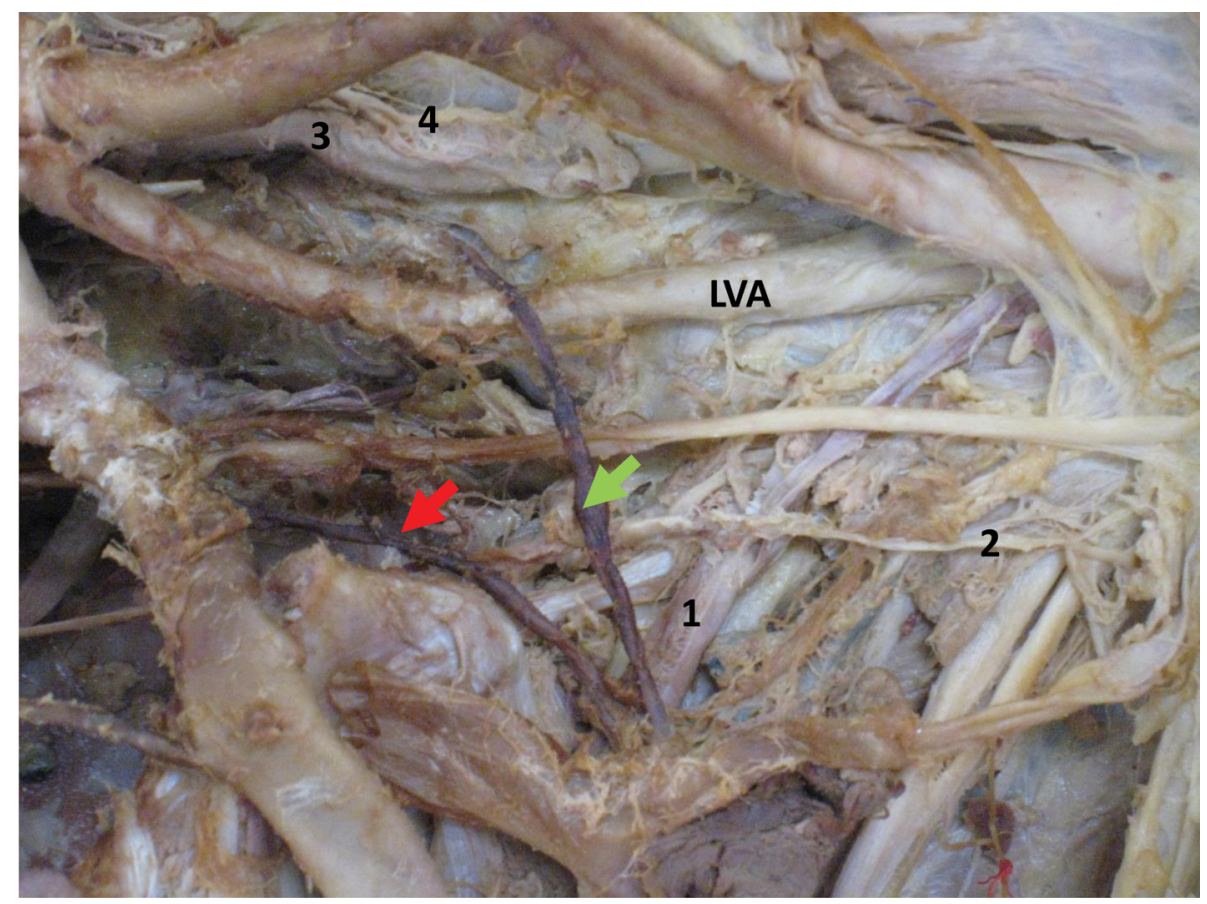

Figure 2. Deeper dissection of the cervicothoracic region. Arrows indicate thoracic ducts; LVA — left vertebral artery; 1 — left vertebral vein; 2 - left phrenic nerve; 3 - oesophagus; 4 - left recurrent laryngeal nerve.

TDs passed superficial to the left phrenic nerve and the left vertebral vein at termination (Fig. 2). Tracing to the posterior mediastinum revealed that the right
TD arose from the right cisterna chyli (L1-L2 level) and soon bifurcated twice (creating a ring formation) before forming a single duct and ascended 


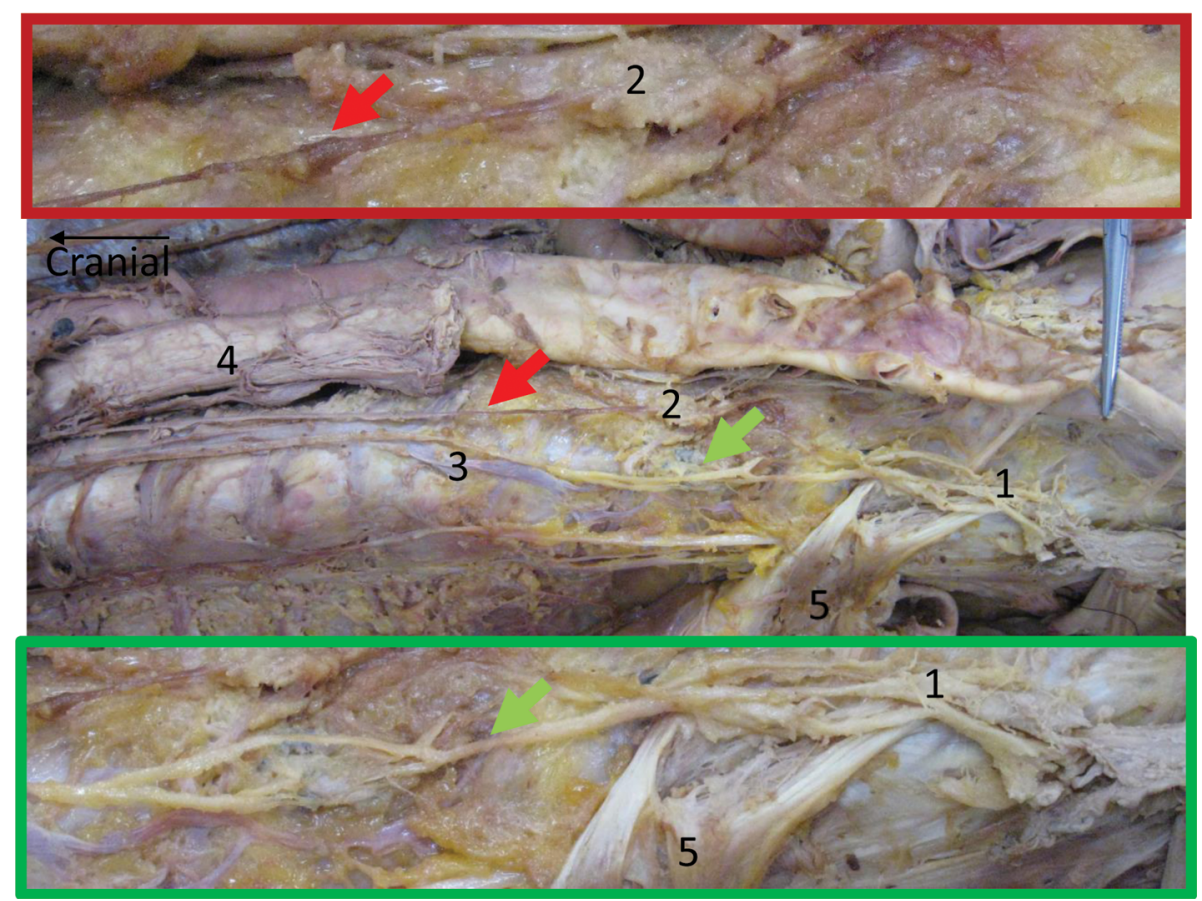

Figure 3. Dissection of posterior mediastinum showing the right and left thoracic ducts (green and red arrows), magnified in lower and upper framed rectangles. The oesophagus was cut and displaced laterally to show the thoracic ducts; 1 - right cisterna chyli; 2 - left cisterna chyli; 3 - Azygos vein; 4 - oesophagus; 5 - diaphragmatic crura.

deep to the oesophagus. The left TD originated from left cisterna chyli (T12 level) and ascended without bifurcation to the superior mediastinum (Fig. 3). Figure 4 shows a lower magnification of the dissected superior and posterior mediastina. Surprisingly, additional variations such as an accessory mental foramen on the right side, an accessory left renal artery and an accessory left arm muscle with an absent musculocutaneous nerve (Fig. 5) were observed. Abnormal bilateral termination of short saphenous vein into the great saphenous vein (data not shown) was also observed.

\section{DISCUSSION}

To the authors' knowledge, this is the first case report highlighting a combination of complete right and left TDs having various relationships with aberrant LVA, in addition to other variations as mentioned above and shown in Figure 2. This pattern of duplicated TDs has not been shown in large-scale anatomical or radiological studies [1, 8, 11]. Focus here is placed on the surgical relevance of double TDs and relationships to the aberrant LVA; the clinical relevance and developmental origin of other variations, and possible relationships to duplicated TDs and aberrant LVA, are beyond the scope of this study. This needs further research in a large number of cases.

Developmentally, the lower two-thirds of the TD are formed from the embryonic right TD, and the upper third is formed from the embryonic left duct. Disturbances during selective atrophy result in extensive TD variations such as the duplication shown in this case $[2,8,11]$. This selective atrophy failure may also explain the anomalous origin of LVA seen here. The presence of two complete right and left TDs terminating into the left venous angle should be considered during oesophagostomy for chylothoraxrelated prevention and treatment via right- or leftsided video-assisted thoracoscopic surgery [1]. This case should also be considered by interventionalists conducting antegrade or retrograde embolisation in chylothorax interventional suites [8]. Chylothorax has also been reported to complicate internal thoracic artery harvesting in coronary heart surgery [3]. Accordingly, as the two TDs were closely related to the ventral and dorsal surfaces of the LVA, there is a risk of related injury during transposition of aberrant LVA [9] or during the various procedures of aortic arch repair [10]. The presence of multiple variations in this case calls for further investigation, and may be considered as a syndrome of anatomical variation. 


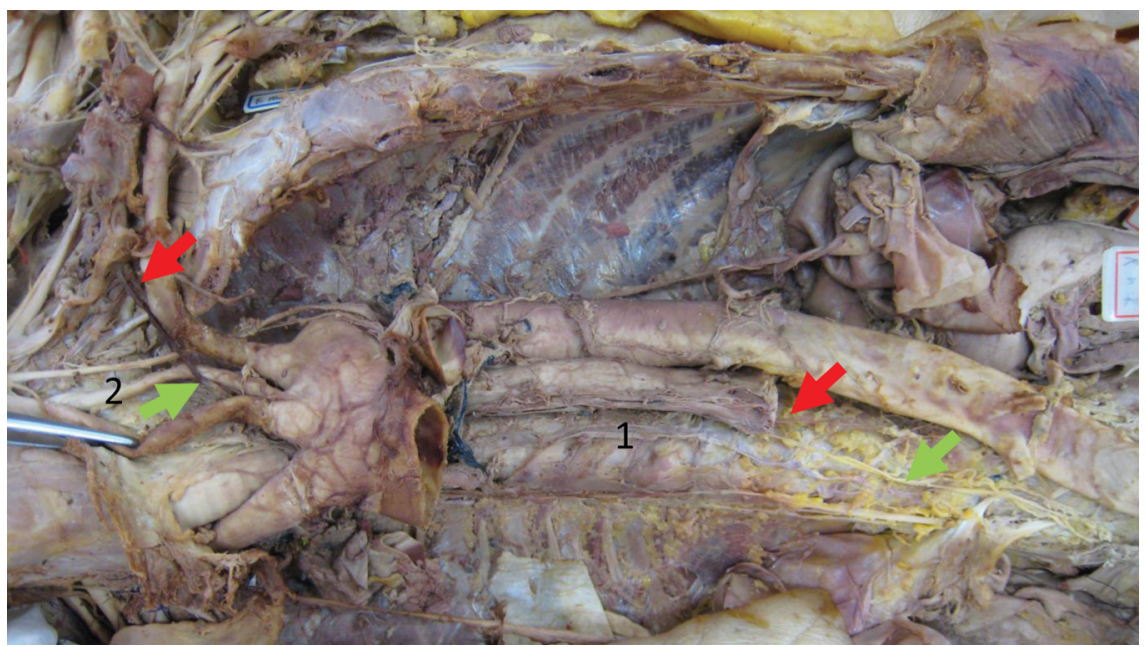

Figure 4. Dissection of superior and posterior mediastinal regions showing thoracic ducts and left vertebral artery; 1 - Azygos vein; 2 - left vertebral artery. The right and left thoracic ducts are indicated by green and red arrows, respectively.
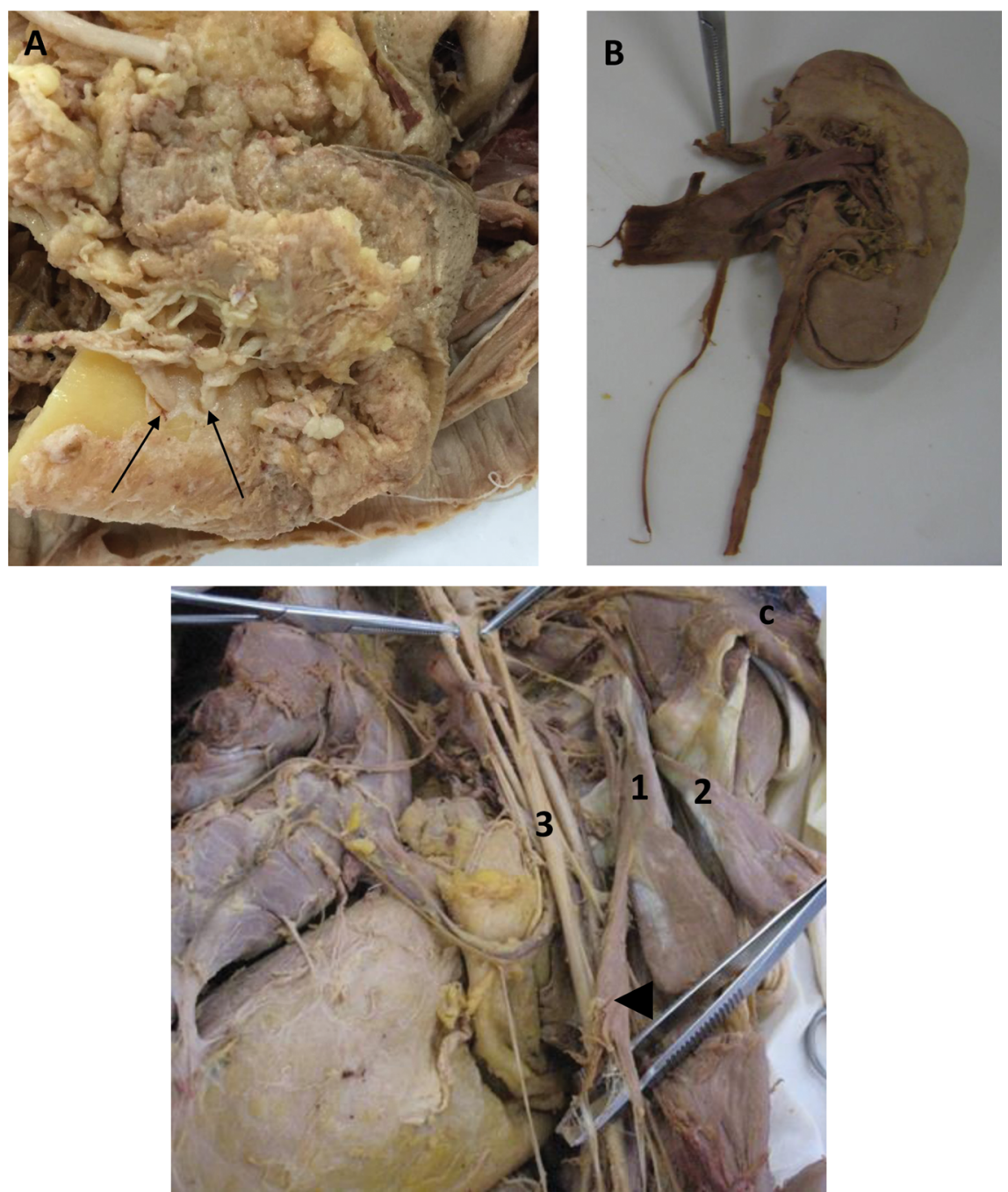

Figure 5. Coexistence of multiple variations in this case. A. Bilateral mental foramina on the right facial side (arrows); B. Accessory left renal artery (held with forceps); C. Accessory muscle (arrow head) in the ventral left arm with absent musculocutaneous nerve; 1 and 2 - short and long heads of biceps brachii, respectively; 3 - median nerve. 


\section{CONCLUSIONS}

This case of duplicated thoracic duct with various relationships to aberrant left-vertebral artery may have important surgical implications.

\section{Acknowledgements}

The authors thank Mika Yaegaki, Akio Kohana, Kaita Koyama, Yasutaka Goto and Kazuya Koyama for their dissection work.

\section{REFERENCES}

1. Abe $T$, Kawai $R$, Uemura $N$, et al. Chylous leakage from a remaining duplicated left-sided thoracic duct after esophagectomy successfully treated by ligation of the leftsided thoracic duct with left-sided video-assisted thoracoscopic surgery with the patient in the prone position. Asian J Endosc Surg. 2016; 9(2): 138-141, doi: 10.1111/ ases.12268, indexed in Pubmed: 27117963.

2. Adachi B. Der Ductus Thoracicus der Jaaner. In: Kihara T, editor. Das Lymhgefässsystem der Jaaner. Tokyo: Kenkyusha. 1953: 1-83.

3. Choong CK, Martinez C, Barner HB. Chylothorax after internal thoracic artery harvest. Ann Thorac Surg. 2006; 81(4): 1507-1509, doi:10.1016/j.athoracsur.2005.02.045, indexed in Pubmed: 16564309.

4. Eid N, Ito Y, Otsuki Y. Surgically Important Relationships of Recurrent and Nonrecurrent Laryngeal Nerves to the Coexisting Variant Vessels. Forensic Med Anat Res. 2015; 03(01): 16-19, doi: 10.4236/fmar.2015.31003.

5. Eid N, Ito $Y$, Otsuki $Y$. Right hepatic artery forming caterpillar hump, perforating Calot's triangle into the cystic plate and associated with a variant branching pattern of the parent vessel. J Hepatobiliary Pancreat Sci. 2015; 22(5): 402-403, doi: 10.1002/jhbp.231, indexed in Pubmed: 25755109.

6. Eid N, Ito $\mathrm{Y}$, Otsuki $\mathrm{Y}$. Thoracic duct relationships to abnormal neurovascular structures in cervicothoracic regions: case study and clinical relevance. Surg Radiol Anat. 2013; 35(10): 969-972, doi: 10.1007/s00276-013-1111-7, indexed in Pubmed: 23536153.

7. Eid N, Ito $\mathrm{Y}$, Shibata MA, et al. Persistent median artery: cadaveric study and review of the literature. Clin Anat. 2011; 24(5): 627-633, doi:10.1002/ca.21127, indexed in Pubmed: 21647963.

8. Johnson OW, Chick JF, Chauhan NR, et al. The thoracic duct: clinical importance, anatomic variation, imaging, and embolization. Eur Radiol. 2016; 26(8): 2482-2493, doi: 10.1007/s00330-015-4112-6, indexed in Pubmed: 26628065.

9. Lee KS, Kim GS, Jung Y, et al. Supraclavicular transposition of aberrant left vertebral artery for hybrid treatment of aortic arch aneurysm: a case report. J Cardiothorac Surg. 2017; 12(1): 9, doi: 10.1186/s13019-017-0574-8, indexed in Pubmed: 28143575.

10. Ohkura K, Shiiya N, Washiyama N, et al. Vertebral artery variations in thoracic aortic patients. Eur J Cardiothorac Surg. 2014; 46(1): 27-31, doi:10.1093/ejcts/ezt609, indexed in Pubmed: 24446475.

11. Okuda I, Udagawa H, Takahashi J, et al. Magnetic resonance-thoracic ductography: imaging aid for thoracic surgery and thoracic duct depiction based on embryological considerations. Gen Thorac Cardiovasc Surg. 2009; 57(12): 640-646, doi: 10.1007/s11748-009-0483-4, indexed in Pubmed:20013098. 